\title{
Fat-mass and obesity-associated gene polymorphisms and weight gain after risperidone treatment in first episode schizophrenia
}

Xueqin Song ${ }^{1 *}$, Lijuan Pang ${ }^{1+}$, Yufang Feng ${ }^{2}$, Xiaoduo Fan ${ }^{3}$, Xue Li ${ }^{1}$, Wei Zhang ${ }^{1}$, Jinsong Gao ${ }^{1}$, Jianjiang Zhang ${ }^{1}$, Katlyn Nemani ${ }^{4}$, Hua Zhang ${ }^{1}$ and Luxian LV $v^{5,6^{*}}$

\begin{abstract}
Background: Obesity induced by antipsychotics severely increases the risk of many diseases and significantly reduces quality of life. Genome Wide Association Studies has identified fat-mass and obesity-associated (FTO) gene associated with obesity. The relationship between the FTO gene and drug-induced obesity is unclear.

Method: Two hundred and fifty drug naïve, Chinese Han patients with first-episode schizophrenia were enrolled in the study, and genotyped for four single nucleotide polymorphisms (SNPs rs9939609, rs8050136, rs1421085 and rs9930506) by the polymerase chain reaction-restriction fragment length polymorphism (PCR-RFLP) and direct sequencing. Body weight and body mass index (BMI) were measured at baseline and six months after risperidone treatment.

Results: At baseline, body weight and BMI of $T$ T homozygotes were lower than those of A allele carriers in rs9939609; body weight of AA homozygotes was higher than those of G allele carriers in rs9930506 (p's < 0.05). After 6 months of risperidone treatment, body weight and BMl of $T$ homozygotes were lower than those of A allele carriers in rs9939609 ( $p$ 's <0.01); body weight and BMI of CC homozygotes were lower than those of A allele carriers in rs8050136 (p's < 0.05); body weight of AA homozygotes was higher than those of G allele carriers in rs9930506 (p's < 0.05). After controlling for age, gender, age of illness onset, disease duration, weight at baseline and education, weight gain of $T T$ homozygotes at 6 months remained to be lower than those of A allele carriers in rs9939609 ( $p<0.01)$; weight gain of CC homozygotes at 6 months was lower than those of A allele carriers in rs8050136 ( $p=0.01$ ). Stepwise multiple regression analysis suggested that, among 4 SNPs, rs9939609 was the strongest predictor of weight gain after 6 months of risperidone treatment $(p=0.001)$.
\end{abstract}

Conclusions: The FTO gene polymorphisms, especially rs9939609, seem to be related to weight gain after risperidone treatment in Chinese Han patients with first episode schizophrenia.

Keywords: FTO gene, Weight gain, Schizophrenia, Single nucleotide polymorphism (SNP)

\section{Background}

Schizophrenia is a psychiatric disorder that is associated with impairment in social and occupational functioning [1]. The use of antipsychotics, especially atypical antipsychotics (AAPs), is associated with serious adverse metabolic effects, including weight gain, hyperlipidemia and glucose intolerance [2], and other [3]. But researches also

\footnotetext{
*Correspondence: sxqzhl|@126.com; Ivluxian@126.com

${ }^{\dagger}$ Equal contributors

'The first Affiliated Hospital/Zhengzhou University, Zhengzhou, China ${ }^{5}$ Henan Province Biological Psychiatry Key Laboratory, Xinxiang Medical University, Xinxiang, China

Full list of author information is available at the end of the article
}

suggested that patients taking AAPs do not necessarily develop these adverse effects, suggesting that differential genetic vulnerability may play a role in antipsychoticassociated metabolic side effects.

The advent of Genome Wide Association Studies (GWAS) emerged as a powerful approach to identify genetic variants associated with common diseases [4]. GWAS has identified a group of loci associated with obesity [5]. In 2007, Frayling et al. [6] and Scuteri et al. [7] found a strong association between common single nucleotide polymorphisms (SNPs) in the first intron of the fat-mass and obesity-associated (FTO) gene on the 
chromosome $16 \mathrm{q} 12.2$, and the risk of obesity. Subsequently, many studies have unequivocally replicated the relationship between FTO gene variants and obesity in children and adults across different populations [8-15], including Han Chinese [13,16-18].

The risk of weight gain is variable among different antipsychotics. Olanzapine and clozapine are associated with the highest risk of weight gain, followed by chloropromzaine, resperidone, and quetiapine [19]. Ziprasidone [20] and aripiprazole belong to the group with the lowest risk of weight gain. The rank order of antipsychotics for inducing weight gain is consistent with that of their metabolic side effects [21], supporting the idea that drug's risk for adverse metabolic changes are strongly associated with its potency for increasing obesity. Risperidone is a common drug used for schizophrenia treatment in China. As we known, Variants of FTO gene (such as rs9939609, rs8050136, rs1421085 and rs9930506) have been consistently reported to be associated with obesity in recent studies [7,12,22,23], but there have been no studies tested the potential role in antipsychotic-related obesity except rs9939609.

The aim of this study was to examine the relationship between FTO gene polymorphisms (rs9939609, rs8050136, rs1421085 and rs9930506) and weight gain after 6 months of risperidone monotherapy in drug-naïve, Chinese Han patients with schizophrenia.

\section{Methods}

\section{Subjects}

All subjects provided written informed consent to participate in the study, which was approved by the Ethics Committee of the First Affiliated Hospital of Zhengzhou University and Henan Mental Hospital. Chinese Han inpatients between 18 and 50 years old diagnosed with firstepisode schizophrenia (disease duration less than 2 years) were recruited. Patients were diagnosed with first-episode schizophrenia according to the criteria of Diagnostic and Statistical Manual of Mental Disorders, Fourth Edition (DSM-IV), and were never previously treated with antipsychotic medications or other psychotropics. The diagnosis of schizophrenia was further determined by two research psychiatrists (X.S. in the First Affiliated Hospital of Zhengzhou University and L.L. in Henan Mental Hospital) using the Structured Clinical Interview for DSM-IV Axis I Disorders. Exclusion criteria included ongoing infections or allergies, history of alcohol or other substance use, pregnancy, known medical conditions that might affect metabolism, history of diabetes or lipid disorder, use of anti-diabetic or lipid-lowering agents or special diets to lower glucose or lipid levels. A complete medical history was obtained from all subjects. All subjects were treated in the two hospitals, and underwent daily physical examination and weekly routine laboratory tests.
After baseline assessment, all patients were treated with risperidone with the dose ranging from $2 \mathrm{mg}$ to $6 \mathrm{mg}$ per day based on the clinical judgment of treating psychiatrists. No other medication was allowed during the study except benzodiazepines for insomnia and anticholinergic agents for dystonia reaction.

\section{Clinical assessment}

Anthropometric assessment was performed at baseline and 6 months after risperidone treatment. Anthropometric measures for each participant were taken after an overnight fast while the subject wore light clothing and no shoes. Weight $(\mathrm{kg})$ and height $(\mathrm{m})$ were measured, and body mass index (BMI) was calculated for all subjects. Symptoms of schizophrenia were assessed using the Positive and Negative Syndrome Scale (PANSS). The clinical assessment was administered by two clinical psychiatrists (L.P. in the First Affiliated Hospital of Zhengzhou University and X.L. in Henan Mental Hospital) who had attended a training session for the proper use of PANSS to ensure the consistency and reliability of the ratings throughout the study. A correlation coefficient above .8 was maintained for the PANSS total score after repeated assessments.

\section{Genotyping}

DNA samples were isolated from peripheral blood using the QIAamp DNA blood kit (QIAGEN GmbH, Hilden, Germany). Genotyping of the FTO SNPs (rs9939609, rs8050136 and rs1421085) was performed using direct sequencing. The PCR-RFLP assay was used to determine the genotype of SNP rs9939506. PCR was carried out in a DNA thermal cycler (Biometra, Goettingen, Germany) using the primers: forward: 5'-CAAAGGTGGGCATAG AGATTG-3'; reverse: 5'-AAGGATTTCTGAGGGACA CA-3'. PCR was performed after the first denaturation at $95^{\circ} \mathrm{C}$ for $2 \mathrm{~min}$; each cycle consisted of denaturation at $95^{\circ} \mathrm{C}$ for $20 \mathrm{sec}$, annealing at $62^{\circ} \mathrm{C}$ for $20 \mathrm{sec}$, and extension at $72^{\circ} \mathrm{C}$ for $30 \mathrm{sec}$. The number of total PCR cycles was 30 . To assess genotyping reproducibility, randomly selected 20\% DNA samples were re-genotyped with $100 \%$ concordance.

\section{Statistical analysis}

The Hardy-Weinberg equilibrium (HWE) and linkage disequilibrium (LD) test of SNPs were done by using the PLINK program [24] and SHEsis. The data were analyzed using SPSS 20.0 (SPSS Inc., Chicago, IL). Demographics and clinical measures were reported using descriptive statistics. Comparisons between genotypes were performed using the Student's t-test for continuous variables and $\chi^{2}$ test for categorical variables. Analysis of covariance was used to examine weight gain at 6 months of risperidone treatment after controlling for potential confounding 
variables. Further, stepwise multiple regression model was used to examine the relative predictive value of gene loci for the risk of weight gain. A p value of less than 0.05 (2-tailed) was used for statistical significance.

\section{Results}

Two hundred and fifty first episode, drug naïve schizophrenia patients were enrolled in the study, and 237 (94.8\%) completed the follow-up assessment after 6 months of risperione treatment (Table 1). Thirteen patients withdrew from the study for various reasons before they reached the 6-month time point (relocation, 5; transportation difficulty, 6; side effects, 2).

The genotype and allele frequencies of 4 SNPs are shown in Table 2. No significant deviation was found between observed values and predicted values from the Hardy-Weinberg equilibrium (Table 2).

To calculate the extent of linkage disequilibrium (LD) in pairwise combinations of the 4 SNPs, we calculated $D^{\prime}$ and $r^{2}$, the normalized LD statistic for all possible pairs of SNPs. The pairwise D' and $\mathrm{r}^{2}$ values are shown in Table 3. Strong LD among the two SNPs (rs9939609 and rs8050136) was observed $\left(r^{2}>0.33\right)$ (Table 3).

At baseline, body weight and BMI of TT homozygotes were lower than those of A allele carriers in rs9939609, and body weight of AA homozygotes was higher than those of G allele carriers in rs9930506 (p's < 0.05). After 6 months of risperidone treatment, body weight and BMI of TT homozygotes were lower than those of A allele carriers in rs9939609 (p's $<0.01$ ), body weight and BMI of CC homozygotes were lower than those of A allele carriers in rs8050136 (p's $<0.05$ ), and body weight of AA homozygotes was higher than those of $\mathrm{G}$ allele carriers in rs9930506 (p's $<0.05$ ). There was no significant

Table 1 Demographic and clinical characteristics of the study sample

\begin{tabular}{ll}
\hline Variables & N or Mean \pm SD \\
\hline Male/female (n) & $128 / 109$ \\
Smoking(yes/no) & $39 / 198$ \\
Age (years) & $27.5 \pm 7.6$ \\
Age of illness onset (years) & $25.0 \pm 5.0$ \\
Disease duration (months) & $7.3 \pm 4.3$ \\
Education (years) & $13.2 \pm 2.9$ \\
Weight (kg) & $57.8 \pm 8.0$ \\
BMI (kg/m ${ }^{2}$ ) & $20.6 \pm 1.9$ \\
PANSS-positive & $23.0 \pm 1.8$ \\
PANSS-negative & $20.9 \pm 1.9$ \\
PANSS-general & $35.0 \pm 3.9$ \\
PANSS-total & $79.5 \pm 4.9$ \\
\hline
\end{tabular}

BMI, body mass index; PANSS, the Positive and Negative Syndrome Scale, including positive symptoms, negative symptoms, general psychopathology subscales.
Table 2 Genotype and allele frequencies of the FTO gene and the hardy Weinberg equilibrium test

\begin{tabular}{ccccccccc}
\hline SNP & Genotype & $\mathbf{n}$ & $\%$ & Allele & Frequency & \multicolumn{2}{c}{ HWE } \\
\cline { 4 - 8 } & & & & & & $\boldsymbol{x}^{\mathbf{2}}$ & $\boldsymbol{P}$ \\
\hline rs9939609 & AA & 4 & 1.7 & $\mathrm{~A}$ & 0.11 & & \\
& AT & 46 & 19.4 & $\mathrm{~T}$ & 0.89 & 0.354 & 0.552 \\
& TT & 187 & 78.9 & & & & \\
rs8050136 & AA & 3 & 1.3 & $\mathrm{~A}$ & 0.10 & & \\
& AC & 43 & 18.1 & $\mathrm{C}$ & 0.90 & 0.107 & 0.743 \\
& CC & 191 & 80.6 & & & & \\
rs1421085 & CC & 3 & 1.3 & $\mathrm{C}$ & 0.11 & & \\
& CT & 45 & 19.0 & $\mathrm{~T}$ & 0.89 & 0.030 & 0.862 \\
& TT & 189 & 79.7 & & & & \\
rs9930506 & GG & 10 & 4.2 & G & 0.17 & & \\
& AG & 59 & 24.9 & A & 0.83 & 2.553 & 0.110 \\
& AA & 168 & 70.9 & & & & \\
\hline
\end{tabular}

HWE: The Hardy-Weinberg equilibrium test.

difference in body weight and BMI between genotypes in other gene loci (p's >0.05) (Table 4).

After controlling for age, gender, age of illness onset, disease duration, weight at baseline and education, weight gain of TT homozygotes was lower than those of A allele carriers in rs9939609 $(\mathrm{p}<0.01)$, and weight gain of CC homozygotes was lower than those of A allele carriers in rs8050136 $(p=0.01)$. There was no significant difference in weight gain at 6 months between genotypes in other gene loci (p's >0.05) (Figure 1). Further, stepwise multiple regression model was developed to identify relevant gene predictors of weight gain at 6 months when other important potential confounding variables, including age, gender, education, disease duration, age of illness onset, weight at baseline were taken into consideration. Only rs9939609 entered into the regression model $(\mathrm{R} 2$ change $=0.039$, df, 1,229, F change $=10.886$, $\mathrm{p}=0.001)$ (Table 5).

\section{Discussion}

To our knowledge, this is the first study to examine the relationship between the four FTO SNPs and

Table 3 Linkage disequilibrium analysis of FTO SNPs

\begin{tabular}{lllll}
\hline $\mathbf{D}^{\prime}$ & rs9939609 & rs8050136 & rs1421085 & rs9930506 \\
\hline$r^{2}$ & & & & \\
rs9939609 & ---- & 0.977 & 0.607 & 0.111 \\
rs8050136 & 0.855 & --- & 0.382 & 0.038 \\
rs1421085 & 0.006 & 0.002 & --- & 0.547 \\
rs9930506 & 0.000 & 0.000 & 0.008 & --- \\
\hline
\end{tabular}

The top right is the value of $D^{\prime}$, and the bottom left is the value of $r^{2}$. 
Table 4 Comparison of body weight and BMI between different genotypes

\begin{tabular}{|c|c|c|c|c|c|c|c|c|c|c|c|c|c|c|c|c|}
\hline \multirow[t]{2}{*}{ Characteristics } & \multicolumn{4}{|l|}{ rs9939609 } & \multicolumn{4}{|l|}{ rs8050136 } & \multicolumn{4}{|l|}{ rs1421085 } & \multicolumn{4}{|l|}{ rs9930506 } \\
\hline & $A A+A T$ & $\pi T$ & $T$ or $x^{2}$ & $\mathbf{P}$ & $A A+A C$ & CC & $t$ or $x^{2}$ & $p$ & $\mathrm{CC}+\mathrm{CT}$ & $\pi T$ & $t$ or $x^{2}$ & $p$ & $\mathrm{GG}+\mathrm{AG}$ & AA & $t$ or $x^{2}$ & $p$ \\
\hline Male/female (n) & $27 / 23$ & $101 / 86$ & 0.000 & 0.999 & $25 / 21$ & $103 / 88$ & 0.003 & 0.959 & $25 / 23$ & $103 / 86$ & 0.090 & 0.764 & $35 / 34$ & $93 / 75$ & 0.423 & 0.516 \\
\hline Age (years) & $29.0 \pm 7.5$ & $26.9 \pm 6.8$ & -1.819 & 0.07 & $29.1 \pm 7.7$ & $26.9 \pm 6.8$ & -1.912 & 0.057 & $27.8 \pm 7.5$ & $27.3 \pm 6.9$ & -0.427 & 0.67 & $27.7 \pm 7.3$ & $27.2 \pm 6.9$ & -0.487 & 0.627 \\
\hline Age of illness onset (years) & $26.2 \pm 5.5$ & $24.7 \pm 4.7$ & 1.949 & 0.053 & $26.3 \pm 5.6$ & $24.7 \pm 4.7$ & 1.772 & 0.81 & $24.8 \pm 5.2$ & $25.1 \pm 4.9$ & -0.393 & 0.695 & $24.9 \pm 4.8$ & $25.0 \pm 5.0$ & -0.174 & 0.86 \\
\hline Disease duration (months) & $6.6 \pm 4.9$ & $7.5 \pm 4.2$ & -1.334 & 0.183 & $6.5 \pm 4.2$ & $7.6 \pm 4.3$ & -1.517 & 0.131 & $7.1 \pm 3.9$ & $7.4 \pm 4.4$ & -0.427 & 0.670 & $7.5 \pm 4.4$ & $7.5 \pm 4.3$ & 0.411 & 0.682 \\
\hline Education (years) & $13.3 \pm 2.5$ & $13.2 \pm 3.0$ & -0.246 & 0.806 & $13.3 \pm 2.6$ & $13.2 \pm 3.0$ & -0.296 & 0.767 & $13.2 \pm 3.0$ & $13.2 \pm 2.9$ & -0.104 & 0.917 & $13.6 \pm 3.1$ & $13.0 \pm 2.9$ & -1.223 & 0.223 \\
\hline \multicolumn{17}{|l|}{ Baseline } \\
\hline Weight (kg) & $63.0 \pm 10.8$ & $59.5 \pm 10.1$ & 2.14 & $0.033^{*}$ & $62.6 \pm 10.9$ & $59.7 \pm 10.2$ & 1.707 & 0.089 & $61.7 \pm 10.1$ & $59.9 \pm 10.4$ & 1.065 & 0.288 & $58.2 \pm 10.1$ & $61.1 \pm 10.4$ & -2.012 & $0.045^{*}$ \\
\hline $\mathrm{BMI}\left(\mathrm{kg} / \mathrm{m}^{2}\right)$ & $22.4 \pm 3.2$ & $21.2 \pm 2.8$ & 2.383 & $0.020^{*}$ & $22.3 \pm 3.3$ & $21.3 \pm 2.8$ & 1.955 & 0.055 & $22.1 \pm 3.0$ & $21.3 \pm 2.9$ & 1.637 & 0.103 & $21.0 \pm 3.0$ & $21.7 \pm 2.9$ & -1.7272 & 0.085 \\
\hline \multicolumn{17}{|l|}{ Six months } \\
\hline Weight (kg) & $71.7 \pm 10.3$ & $67.0 \pm 9.8$ & 2.949 & $0.004^{*}$ & $71.1 \pm 10.4$ & $67.2 \pm 9.9$ & 2.354 & $0.019^{*}$ & $68.9 \pm 9.8$ & $67.7 \pm 10.1$ & 0.714 & 0.476 & $65.8 \pm 10.0$ & $68.9 \pm 9.984$ & -2.132 & $0.034^{*}$ \\
\hline BMI (kg/m2) & $25.5 \pm 3.0$ & $23.9 \pm 2.7$ & 3.628 & $0.000^{*}$ & $25.4 \pm 3.0$ & $24.0 \pm 2.7$ & 3.009 & $0.003^{*}$ & $24.7 \pm 2.8$ & $24.2 \pm 2.8$ & 1.215 & 0.226 & $23.8 \pm 3.0$ & $24.5 \pm 2.7$ & -1.786 & 0.075 \\
\hline
\end{tabular}

BMI, body mass index.

${ }^{*} P<0.05$. 


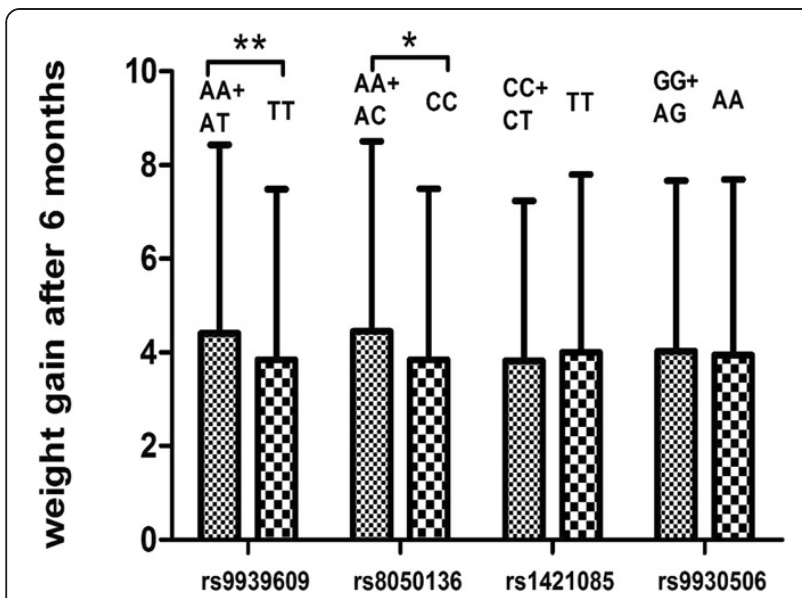

Figure 1 Comparison of weight gain after 6 months of risperidone treatment between different genotypes.

antipsychotic-associated weight gain in drug naïve, Chinese Han patients with first episode schizophrenia. Our study suggested that SNPs rs9939609 and rs8050136 of FTO gene might play an important role in weight gain after 6 months of risperidone treatment. Our study did not find significant relationships between SNPs rs9930506 and rs1421085 of FTO gene and antipsychotic-associated weight gain.

Our results suggested that A allele in rs9939609 and rs8050136 could be a risk allele of weight gain in firstepisode schizophrenia; the findings are consistent with the results from a previous study in a healthy Japanese human sample [25], but they found no significant difference in BMI across different medications. Other studies also found that the FTO gene is associated with obesity or obesity-related diseases in non-schizophrenia populations [5,6]. Liu et al. [8] identified positive associations between SNPs rs9939609 and rs8050136 of FTO gene and the risk to develop type 2 diabetes in the Chinese Han population. Ahmad et al. [26] found that the SNP

Table 5 Multiple regression analysis: rs9939609 predicts weight gain at 6 months after controlling for age, gender, education, disease duration, age of illness onset and weight at baseline

\begin{tabular}{lllll}
\hline Predictors & R2 change & df & F change & P \\
\hline $\begin{array}{l}\text { Step 1: age, gender, education, } \\
\text { disease duration, age of illness }\end{array}$ & 0.131 & 6,230 & 5.782 & $<0.001$ \\
$\begin{array}{l}\text { onset, weight at baseline } \\
\text { Step 2: rs9939609 }\end{array}$ & 0.039 & 1,229 & 10.886 & 0.001 \\
\hline
\end{tabular}

Potential confounding variables including age, gender, education, disease duration, age of illness onset and weight at baseline were entered first (forced entry, Step 1); rs9939609, rs8050136, rs1421085 and rs9930506 genes were considered next (stepwise, Step 2), and rs9939609 gene was the only variable that entered into the regression model. rs8050136 polymorphism was associated with obesity and other metabolic problems in healthy US women. Few studies have investigated the relationship between FTO SNP polymorphisms and antipsychotic-associated weight gain with inconsistent findings [27-30]. For example, Tiwari et al. [31] found that the SNP rs9922047 polymorphism of FTO gene was associated with percent weight gain in patients with schizophrenia; Perez-Iglesias et al. [28] found the magnitude of weight gain was similar among 3 genotypes of the SNP rs9939609 of FTO gene in patients with schizophrenia after 1 year of antipsychotic treatment.

The FTO gene is the first and most robustly replicated gene that is related to body weight and fat mass [32,33]. However, the underlying mechanisms remain to be unclear. FTO gene is highly expressed in the brain, particularly in the hypothalamus, which governs energy balance by regulating appetite and food intake [28]. Furthermore, it has been described that the FTO gene encodes a 2-oxoglutarate-dependent nucleic acid demethylase $[34,35]$, which is a transcription coactivator related to energy homeostasis [34]. The rs9939609 is in the first intron of FTO gene. Frayling et al. [6] first reported that rs9939609 is association with obesity-related traits in both adults and children of European descents. Chang et al. [16] found that rs9939609 A allele is strongly associated with obesity and BMI in the Chinese population; another study in Chinese and Malays who lived in Singapore also reported a significant association between rs9939609 and obesity [17]. For the first time, our study found that s9939609 is associated with weight gain after risperidone treatment in patients with schizophrenia.

Our research has some limitations. First, the sample size is relatively small and larger studies are needed to confirm our findings. Second, patients on other antipsychotics were not included in the study. Third, there was lack of a healthy control group. Therefore it is unclear if the effect sizes of the genetic markers (4 SNPs) in patients with schizophrenia are the same as in the general population. Lastly, potential confounding variables that could contribute to weight gain such as dosage of risperidone; environmental factors like physical activity, diet, employment status, as well as other genetic risk factors were not measured in the present study. In order to better understand the effect of genetic factors on antipsychoticassociated weight gain, future studies should examine gene-environmental interaction and gene-gene interaction to explore the role of FTO gene polymorphisms in antipsychotic-associated weight gain.

\section{Conclusion}

Our findings suggest that FTO SNP rs9939609 seem to be related to weight gain after risperidone treatment in Chinese Han patients with first episode schizophrenia. 


\section{Abbreviations}

FTO gene: At-mass and obesity-associated gene; SNP: Single nucleotide polymorphisms; PCR-RFLP: Polymerase chain reaction-restriction fragment length polymorphism; BMI: Body mass index; AAPs: Atypical antipsychotics; GWAS: Genome Wide Association Studies; PANSS: Positive and Negative Syndrome Scale; HWE: Hardy-Weinberg equilibrium; LD: Linkage disequilibrium; DSM-IV: Diagnostic and statistical manual of mental disorders, fourth edition.

\section{Competing interests}

The authors declare that they have no competing interests.

\section{Authors' contributions}

Xueqin Song and Lijuan Pang were responsible for the analysis and interpretation of the data for this paper. All authors contributed to the writing of the paper. All authors read and approved the final manuscript.

\section{Acknowledgements}

Funding for this study was provided by the National Natural Science Foundation of China (No.30971058 to X-QS; No.81071090to L-XL), the Natural Science Foundation of Henan (No.102300413208, 112300413226 to L-XL), the Youth Fund of the First Affiliated Hospital of Zhengzhou University (to L-J P).

\section{Author details}

${ }^{1}$ The first Affiliated Hospital/Zhengzhou University, Zhengzhou, China. ${ }^{2}$ Qingdao Mental Health Center, Qingdao, China. ${ }^{3}$ Psychotic Disorders Program, UMass Memorial Medical Center/University of Massachusetts Medical School, Worcester, MA, UK. 4Tufts University School of Medicine, Boston, MA, UK. ${ }^{5}$ Henan Province Biological Psychiatry Key Laboratory, Xinxiang Medical University, Xinxiang, China. ${ }^{6}$ Henan Province Mental Hospital, the Second Affiliated Hospital/Xinxiang Medical University, Xinxiang, China.

Received: 13 March 2014 Accepted: 7 September 2014

Published: 2 October 2014

\section{References}

1. Thabet S, Ben Nejma M, Zaafrane F, Gaha L, Ben Salem K, Romdhane A, Nour M, Jrad BB: Association of the Met-196-Arg variation of human tumor necrosis factor receptor 2 (TNFR2) with paranoid schizophrenia. J Mol Neurosci 2011, 43(3):358-363.

2. Meyer JM, Koro CE: The effects of antipsychotic therapy on serum lipids: a comprehensive review. Schizophr Res 2004, 70(1):1-17.

3. Lieberman JA, Stroup TS, McEvoy JP, Swartz MS, Rosenheck RA, Perkins DO, Keefe RS, Davis SM, Davis CE, Lebowitz BD, Severe J, Hsiao JK: Clinical Antipsychotic Trials of Intervention Effectiveness (CATIE) Investigators: Effectiveness of antipsychotic drugs in patients with chronic schizophrenia. New Engl J Med 2005, 353(12):1209-1223.

4. Tung YCL, Yeo GS: From GWAS to biology: lessons from FTO. Ann N Y Acad Sci 2011, 1220(1):162-171

5. Loos RJ: Genetic determinants of common obesity and their value in prediction. Best Pract Res Clin Endocrinol Metab 2012, 26(2):211-226.

6. Frayling TM, Timpson NJ, Weedon MN, Zeggini E, Freathy RM, Lindgren CM, Perry JR, Elliott KS, Lango H, Rayner NW, Shields B, Harries LW, Barrett JC, Ellard S, Groves CJ, Knight B, Patch AM, Ness AR, Ebrahim S, Lawlor DA, Ring SM, Ben-Shlomo Y, Jarvelin MR, Sovio U, Bennett AJ, Melzer D, Ferrucci L, Loos RJ, Barroso I, Wareham NJ, et al: A common variant in the FTO gene is associated with body mass index and predisposes to childhood and adult obesity. Science 2007, 316(5826):889-894.

7. Scuteri A, Sanna S, Chen WM, Uda M, Albai G, Strait J, Najjar S, Nagaraja R, Orrú M, Usala G, Dei M, Lai S, Maschio A, Busonero F, Mulas A, Ehret GB, Fink AA, Weder AB, Cooper RS, Galan P, Chakravarti A, Schlessinger D, Cao A, Lakatta E, Abecasis GR: Genome-wide association scan shows genetic variants in the FTO gene are associated with obesity-related traits. PLOS Genet 2007, 3(7):e115.

8. Liu Y, Liu Z, Song Y, Zhou D, Zhang D, Zhao T, Chen Z, Yu L, Yang Y, Feng G, Li J, Zhang J, Liu S, Zhang Z, He L, Xu H: Meta-analysis added power to identify variants in FTO associated with type 2 diabetes and obesity in the Asian population. Obesity 2010, 18(8):1619-1624.

9. Rampersaud E, Mitchell BD, Pollin TI, Fu M, Shen H, O'Connell JR, Ducharme J, Hines S, Sack P, Naglieri R, Shuldiner AR, Snitker S: Physical activity and the association of common FTO gene variants with body mass index and obesity. Arch Intern Med 2008, 168(16):1791.

10. Song Y, You NC, Hsu YH, Howard BV, Langer RD, Manson JE, Nathan L, Niu T, Tinker FL, Liu S: FTO polymorphisms are associated with obesity but not diabetes risk in postmenopausal women. Obesity 2008, 16(11):2472-2480

11. Grant SF, Li M, Bradfield JP, Kim CE, Annaiah K, Santa E, Glessner JT, Casalunovo T, Frackelton EC, Otieno FG, Shaner JL, Smith RM, Imielinski M, Eckert AW, Chiavacci RM, Berkowitz Rl, Hakonarson H: Association analysis of the FTO gene with obesity in children of Caucasian and African ancestry reveals a common tagging SNP. PLoS One 2008, 3(3):e1746.

12. Mačeková S, Bernasovský I, Gabriková D, Bôžiková A, Bernasovská J, Boroňová I, Behulová $R$, Svíčková $P$, Petrejčíková $E$, Soták $M$, Sovičová $A$, Carnogurská J: Association of the FTO rs9939609 polymorphism with obesity in Roma/Gypsy population. Am J Phys Anthropol 2012 147(1):30-34.

13. Fang H, Li Y, Du S, Hu X, Zhang Q, Liu A, Ma G: Variant rs9939609 in the FTO gene is associated with body mass index among Chinese children. BMC Med Genet 2010, 11(1):136.

14. Zavattari P, Loche A, Pilia S, Ibba A, Moi L, Guzzetti C, Casini MR, Loche S: rs9939609 in the FTO gene is associated with obesity but not with several biochemical parameters in Sardinian obese children. Ann Hum Genet 2011, 75(6):648-654.

15. Rodríguez-López R, González-Carpio M, Serrano MV, Torres G, de Cáceres MT G, Herrera T, Román A, Rubio M, Méndez P, Hernández-Sáez R, Núñez M, Luengo LM: Association of FTO gene polymorphisms and morbid obesity in the population of Extremadura (Spain). Endocrinología y nutrición: órgano de la Sociedad Española de Endocrinología y Nutrición 2010, 57(5):203.

16. Chang Y-C, Liu PH, Lee WJ, Chang TJ, Jiang YD, Li HY, Kuo SS, Lee KC, Chuang LM: Common variation in the fat mass and obesity-associated (FTO) gene confers risk of obesity and modulates BMI in the Chinese population. Diabetes 2008, 57(8):2245-2252.

17. Tan JT, Dorajoo R, Seielstad M, Sim XL, Ong RT, Chia KS, Wong TY, Saw SM, Chew SK, Aung T, Tai ES: FTO variants are associated with obesity in the Chinese and Malay populations in Singapore. Diabetes 2008, 57(10):2851-2857

18. Xi B, Shen Y, Zhang M, Liu X, Zhao X, Wu L, Cheng H, Hou D, Lindpaintner K, Liu L, Mi J, Wang X: The common rs9939609 variant of the fat mass and obesity-associated gene is associated with obesity risk in children and adolescents of Beijing, China. BMC Med Genet 2010, 11(1):107.

19. Lett T, Wallace TJ, Chowdhury NI, Tiwari AK, Kennedy JL, Müller DJ: Pharmacogenetics of antipsychotic-induced weight gain: review and clinical implications. Mol Psychiatry 2012, 17(3):242-266.

20. Park S, Kim MS, Namkoong C, Park MH, Hong JP: The effect of ziprasidone on body weight and energy expenditure in female rats. Metabolism 2012, 61(6):787-793.

21. Newcomer JW: Metabolic syndrome and mental illness-page 4. Am Manag Care 2007, 13:S170-S177.

22. Park SL, Cheng I, Pendergrass SA, Kucharska-Newton AM, Lim U, Ambite JL, Caberto CP, Monroe KR, Schumacher F, Hindorff LA, Oetjens MT, Wilson S, Goodloe RJ, Love SA, Henderson BE, Kolonel LN, Haiman CA, Crawford DC, North KE, Heiss G, Ritchie MD, Wilkens LR, Le Marchand L: Association of the FTO obesity risk variant rs 8050136 with percentage of energy intake from fat in multiple racial/ethnic populations the page study. Am J Epidemiol 2013, 178(5):780-790

23. Liu C, Mou S, Cai Y: FTO Gene Variant and Risk of Overweight and Obesity among Children and Adolescents: a Systematic Review and Meta-Analysis. PLoS One 2013, 8(11):e82133.

24. Purcell S, Neale B, Todd-Brown K, Thomas L, Ferreira MA, Bender D, Maller J, Sklar P, de Bakker PI, Daly MJ, Sham PC: PLINK: a tool set for wholegenome association and population-based linkage analyses. Am J Hum Genet 2007, 81(3):559-575.

25. Watanabe SY, Iga J, Numata S, Nakataki M, Tanahashi T, Itakura M, Ohmori T: Association study of fat-mass and obesity-associated gene and body mass index in Japanese patients with schizophrenia and healthy subjects. Clin Psychopharmacol Neurosci 2012, 10(3):185-189.

26. Ahmad T, Lee IM, Paré G, Chasman DI, Rose L, Ridker PM, Mora S: Lifestyle interaction with fat mass and obesity-associated (FTO) genotype and risk of obesity in apparently healthy US women. Diabetes Care 2011, 34(3):675-680 
27. Jassim G, Fernø J, Theisen FM, Haberhausen M, Christoforou A, Håvik B, Gebhardt S, Remschmidt H, Mehler-Wex C, Hebebrand J, Lehellard S, Steen VM: Association study of energy homeostasis genes and antipsychotic-induced weight gain in patients with schizophrenia. Pharmacopsychiatry 2011, 44(01):15-20.

28. Perez-Iglesias R, Mata I, Amado JA, Berja A, Garcia-Unzueta MT, Martínez García O, Arranz MJ, Vazquez-Barquero JL, Crespo-Facorro B: Effect of FTO, SH2B1, LEP, and LEPR polymorphisms on weight gain associated with antipsychotic treatment. J Clin Psychopharmacol 2010, 30(6):661-666.

29. Reynolds GP: Pharmacogenetic Aspects of Antipsychotic Drug-induced Weight Gain-A Critical Review. Clin Psychopharmacol Neurosci 2012, 10(2):71-77.

30. Reynolds GP, Yevtushenko OO, Gordon S, Arranz B, San L, Cooper SJ: The obesity risk gene FTO influences body mass in chronic schizophrenia but not initial antipsychotic drug-induced weight gain in first-episode patients. Int I Neuropsychopharmacol 2013, 16(6):1421-1425.

31. Tiwari HK, Patki A, Lieberman J, Stroup TS, Allison DB, Leibel RL, Chung WK: Association of allelic variation in genes mediating aspects of energy homeostasis with weight gain during administration of antipsychotic drugs (CATIE Study). Front Genet 2011. doi:10.3389/fgene.2011.00056.

32. McCaffery JM, Papandonatos GD, Huggins GS, Peter I, Kahn SE, Knowler WC, Hudnall GE, Lipkin EW, Kitabchi AE, Wagenknecht LE, Wing RR: Genetic subgroup of look ahead; look ahead research group: FTO predicts weight regain in the look ahead clinical trial. Int J Obes (Lond) 2013, 37(12):1545-1552.

33. Shinozaki K, Okuda M: The effects of fat mass and obesity-associated gene variants on the body mass index among ethnic groups and in children and adults. Indian J Endocrinol Metab 2012, 16(Suppl 3):S588.

34. Dlouhá D: FTO gene and his role in genetic determination of obesity. Vnitr Lek 2012, 58(3):208.

35. Hubacek JA, Pitha J, Adamkova V, Lanska V, Poledne R: A common variant in the FTO gene is associated with body mass index in males and postmenopausal females but not in premenopausal females. Czech post-MONICA and 3PMFs studies. Clin Chem Lab Med 2009, 47(4):387-390.

doi:10.1186/1744-9081-10-35

Cite this article as: Song et al.: Fat-mass and obesity-associated gene polymorphisms and weight gain after risperidone treatment in first episode schizophrenia. Behavioral and Brain Functions 2014 10:35.

\section{Submit your next manuscript to BioMed Central and take full advantage of:}

- Convenient online submission

- Thorough peer review

- No space constraints or color figure charges

- Immediate publication on acceptance

- Inclusion in PubMed, CAS, Scopus and Google Scholar

- Research which is freely available for redistribution 